\title{
EXTENSION OF WEYL-HEISENBERG WAVE PACKET BESSEL SEQUENCES TO DUAL FRAMES IN $L^{2}(\mathbb{R})$
}

\author{
DEEPSHIKHA AND L. K. VASHISHT
}

Abstract. Christensen et al. proved in [Extensions of Bessel sequences to dual pairs of frames, Appl. Comput. Harmon. Anal., 34 (2013), 224-233] that in any separable Hilbert space, any pairs of Bessel sequences (even if the given Bessel system is Gabor system in $L^{2}(\mathbb{R})$ ) can be extended to a pair of dual frames. In this paper, we extend results by Christensen et al. to a pair of Bessel sequences in $L^{2}(\mathbb{R})$ having wave packet structure to a pair of dual frames such that extension have wave packet structure as well. We present sufficient conditions for the extension of a pair of Bessel sequences to wave packet type dual frames for $L^{2}(\mathbb{R})$. Several examples and counter-examples are given to illustrate our results.

Mathematics subject classification (2010): 42C15, 42C30, 42C40.

Keywords and phrases: Hilbert frame, wave packet system, Bessel sequence.

\section{REFERENCES}

[1] P. G. CasazZa And G. Kutyniok, Finite Frames: Theory and Applications, Birkhäuser, 2012.

[2] P. G. CASAZZA And N. LeOnhard, Classes of finite equal norm Parseval frames, Contemporary Mathematics, 451 (2008), 11-13.

[3] O. Christensen, An Introduction to Frames and Riesz Bases, Birkhäuser, Boston, 2002.

[4] O. Christensen, Frames and Bases: An Introductory Course, Birkhäuser, Boston, 2008.

[5] O. CHRISTENSEN AND A. RAHIMI, Frame properties of wave packet systems in $L^{2}\left(\mathbb{R}^{d}\right)$, Advances in Computational Mathematics, 29 (2008), 101-111.

[6] O. Christensen AND A. RAHIMI, An introduction to wave packet Systems in $L^{2}(\mathbb{R})$, Indian Journal of Industrial and Applied Mathematics, 1 (2008), 42-57.

[7] O. Christensen, H. O. Kim And R. Y. Kim, On Parseval wavelet frames with two or three generators via the unitary extension principle, Canadian Mathematical Bulletin, 57 (2) (2014), 254-263.

[8] O. Christensen, H. O. Kim And R. Y. Kim, Extensions of Bessel sequences to dual pairs of frames, Applied and Computational Harmonic Analysis, 34 (2013), 224-233.

[9] A. Cordoba And C. FeFFERMAn, Wave packets and Fourier integral operators, Communications in Partial Differential Equations, 3 (11) (1978), 979-1005.

[10] W. Czaja, G. Kutyniok And D. Speegle, The geometry of sets of prameters of wave packets, Applied and Computational Harmonic Analysis, 20 (2006), 108-125.

[11] I. Daubechies, A. Grossmann And Y. Meyer, Painless nonorthogonal expansions, Journal of Mathematical Physics, 27 (1986), 1271-1283.

[12] I. DAubechies, Ten Lectures on Wavelets, SIAM, Philadelphia, 1992.

[13] DEEPSHIKHA AND L. K. VASHISHT, Extension of Bessel sequences to dual frames in Hilbert spaces, submitted.

[14] R. J. DufFin And A. C. SChaEfFER, A class of nonharmonic Fourier series, Transactions of the American Mathematical Society, 72 (1952), 341-366.

[15] D. GABOR, Theory of communications, Journal of Inst. Electrical Engineering, 93 (3) (1946), 429_ 457.

[16] D. HAn, Dilations and completions for Gabor systems, Journal of Fourier Analysis and Applications, 15 (2) (2009), 201-217. 
[17] E. Hernández, D. Labate AND G. WeISs, A unified characterization of reproducing systems generated by a finite family II, Journal of Geometric Analysis, 12 (4) (2002), 615-662.

[18] E. HeRnándeZ, D. LABATE, G. Weiss AND E. Wilson, Oversampling, quasi-affine frames and wave packets, Applied and Computational Harmonic Analysis, 16 (2004), 111-147.

[19] D. Labate, G. Weiss AND E. Wilson, An approach to the study of wave packet systems, Contemporary Mathematics, 345 (2004), 215-235.

[20] M. LACEY AND C. Thiele, $L^{p}$ estimates on the bilinear Hilbert transform for $2<p<\infty$, Annals of Mathematics, 146 (1997), 693-724.

[21] M. LACEY And C. THIELE, On Calderón's conjecture, Annals of Mathematics, 149 (1999), 475-496.

[22] D. F. Li AND W. Sun, Expansion of frames to tight frames, Acta Mathematica Sinica (English Series), 25 (2009), 287-292. 